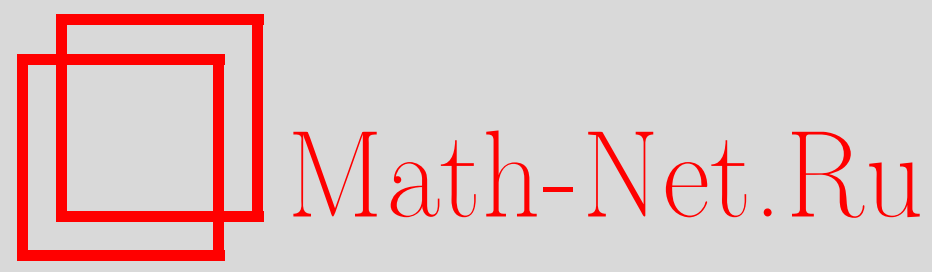

А. В. Хлямков, Замечание о сходимости метода парабол, Матем. заметки, 1998, том 63, выпуск 2, 309

DOI: https://doi.org/10.4213/mzm1282

Использование Общероссийского математического портала Math-Net.Ru подразумевает, что вы прочитали и согласны с пользовательским соглашением http://www.mathnet.ru/rus/agreement

Параметры загрузки:

IP: 3.85 .7 .115

26 апреля 2023 г., 15:34:29

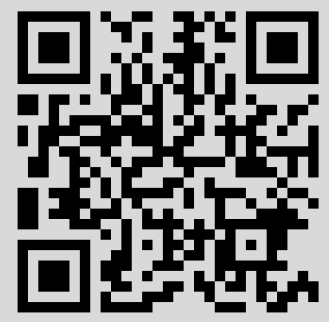




\section{ЗАМЕЧАНИЕ О СХОДИМОСТИ МЕТОДА ПАРАБОЛ}

\section{А. В. Хлямков}

Метод парабол является одним из наиболее удобных и широко применяемых способов нахождения действительных и комплексных корней произвольного многочлена

$$
P(z)=a_{0} z^{m}+a_{1} z^{m-1}+\cdots+a_{m} .
$$

Как известно (см., например, [1]), этот метод состоит в следующем. Выбирается произвольная тройка $z_{0}, z_{1}, z_{2}$ различных точек комплексной плоскости и строится квадратичный интерполяционный многочлен $Q(z)$, имеющий те же значения, что и $P(z)$ в $z_{0}, z_{1}, z_{2}$. Пусть $z_{3}$ - ближайштй к $z_{2}$ корень $Q(z)$. Тройка $z_{0}, z_{1}, z_{2}$ заменяется тройкой $z_{1}, z_{2}, z_{3}$, с которой затем поступаем аналогично, и т.д. Последовательность $\left\{z_{n}\right\}$ практически всегда сходится к одному из корней $P(z)$. После понижения степени также находятся и остальные корни.

Хотя сходимость этого метода для произвольных многочленов при произвольных начальных условиях не доказана, не зарегистрировано ни одного случая, когда этот метод не сходится или сходится медленно (см. [1, с. 329], [2, с. 221-229]).

Теорема. Существует такой многочлен и такие начальные точки, что на некоторой итерачии интерполячионный многочлен вырождается в константу.

ДоКАЗАТЕЛЬСТво. Пусть

$$
P(z)=3 z^{4}-38 z^{3}+128 z^{2}-58 z-131
$$

и $z_{0}=3, z_{1}=-1, z_{2}=7$. На первом шаге итерационного процесса получаем интерполяционньй многочлен $Q_{0}(z)=-4 z^{2}+100$, откуда $z_{3}=5$. Повторная итерация для тройки точек $-1,7,5$ приводит к интерполяционному многочлену $Q_{1}(z)=4 z^{2}-48 z+44$, откуда $z_{4}=1$. Так как $P\left(z_{2}\right)=P\left(z_{3}\right)=P\left(z_{4}\right)=-96$, получаем $Q_{2}(z)=-96$, что и требовалось доказать.

Разумеется, значения исходного многочлена могут совпадать уже в начальных точках, но такие исходные данные представляют меньший интерес, так как в этом случае мы могли бы сразу поменять начальные точки.

СлЕДСтвиЕ 1. Существует такое $\varepsilon$, такой многочлен и такие начальные точки, что метод парабол не дает $\varepsilon$-приближсения $к$ корню многочлена.

ДоКАЗАТЕЛЬСТВО. Возьмем многочлен и начальные точки из доказательства теоремы, примем $\varepsilon=0.2$. В полученном после остановки метода множестве приближений $\left\{z_{0}, z_{1}, z_{2}, z_{3}, z_{4}\right\}$ ни одно число не является $\varepsilon$-приближением к какому-либо корню исходного многочлена.

Непосредственно отсюда вытекает

Следствие 2. Метод парабол не является сходящимся при любых начальных данных.

Сказанное ни в коей мере не умаляет практической ценности метода. Во-первых, подобные ситуации естественно рассматривать как исключительные и поэтому не имеющие серьезного значения для практики. Во-вторых, существуют различные приемы выхода из подобных тупиков. Вопросы сходимости таких модифицированных алгоритмов требуют, естественно, отдельного изучения. Что же касается метода парабол "в чистом виде", то здесь, по-видимому, уместно ставить вопрос о сходимости метода при почти всех (но не всех) начальных точках.

\section{СПИСОК ЦИТИРОВАННОЙ ЛИТЕРАТУРЫ}

1. Бахвалов Н. С., ЖКидков Н.П., Кобельков Г. М. Численные методы. М.: Наука, 1987. 2. Воеводин В. В. Численные методы алгебры. Теория и алгорифмы. М.: Наука, 1966. 